\title{
Self-Crosslinked Ellipsoidal Poly(Tannic Acid) Particles for Bio-Medical Applications
}

\author{
Nurettin Sahiner ${ }^{1,2}$ \\ 1 Nanoscience and Technology Research and Application Center, Department of Chemistry, Terzioglu Campus, \\ Canakkale Onsekiz Mart University, 17100 Canakkale, Turkey; nsahiner@usf.edu or sahiner71@gmail.com; \\ Tel.: +1-813-974-0135; Fax: +1-813-974-5621 \\ 2 Department of Ophthalmology, Morsani College of Medicine, University of South Florida, 12,901 Bruce B \\ Downs B. Downs Blv., MDC 21, Tampa, FL 33612, USA
}

check for updates

Citation: Sahiner, N. Self-Crosslinked Ellipsoidal Poly(Tannic Acid) Particles for Bio-Medical Applications. Molecules 2021, 26, 2429. https://doi.org/ $10.3390 /$ molecules26092429

Academic Editor: Ivan Gitsov

Received: 31 March 2021

Accepted: 21 April 2021

Published: 22 April 2021

Publisher's Note: MDPI stays neutral with regard to jurisdictional claims in published maps and institutional affiliations.

Copyright: (C) 2021 by the author. Licensee MDPI, Basel, Switzerland. This article is an open access article distributed under the terms and conditions of the Creative Commons Attribution (CC BY) license (https:// creativecommons.org/licenses/by/ $4.0 /)$.

\begin{abstract}
Self-crosslinking of Tannic acid (TA) was accomplished to obtain poly(tannic acid) ( $p$ (TA)) particles in single step, surfactant free media using sodium periodate $\left(\mathrm{NaIO}_{4}\right)$ as an oxidizing agent. Almost monodisperse $p$ (TA) particles with $981 \pm 76 \mathrm{~nm}$ sizes and $-22 \pm 4 \mathrm{mV}$ zeta potential value with ellipsoidal shape was obtained. Only slight degradation of $p(\mathrm{TA})$ particles with $6.8 \pm 0.2 \%$ was observed at pH 7.4 in PBS up to 15 days because of the irreversible covalent formation between TA units, suggesting that hydrolytic degradation is independent from the used amounts of oxidation agents. $p$ (TA) particles were found to be non-hemolytic up to $0.5 \mathrm{mg} / \mathrm{mL}$ concentration and found not to affect blood clotting mechanism up to $2 \mathrm{mg} / \mathrm{mL}$ concentration. Antioxidant activity of $p$ (TA) particles was investigated by total phenol content (TPC), ferric reducing antioxidant potential (FRAP), trolox equivalent antioxidant capacity (TEAC), total flavanoid content (TFC), and Fe (II) chelating activity. $p$ (TA) particles showed strong antioxidant capability in comparison to TA molecules, except FRAP assay. The antibacterial activity of $p$ (TA) particles was investigated by micro-dilution technique on E. coli as Gram-negative and S. aureus as Gram-positive bacteria and found that $p$ (TA) particles are more effective on $S$. aureus with over $50 \%$ inhibition at $20 \mathrm{mg} / \mathrm{mL}$ concentration attained.
\end{abstract}

Keywords: tannic acid particles; self-crosslinked flavonoid; polyphenolic microgel/nanogel; antioxidant; antibacterial; bio-medicinal applications

\section{Introduction}

Tannic acid (TA) is a plant-based polyphenolic and can be found in coffee, tea, wine, pomegranate, grapes, cranberries, etc. [1,2]. A TA molecule is composed of a central glucose unit connected with five gallic acid groups via ester bond, and each of these gallic acids is also connected with one gallic acid, resulting in ten gallic acids in a single TA molecule $[3,4]$. TA molecule has substantial natural properties to be exploited for biomedical use such as antibacterial, radical scavenging, and anti-cancer, etc. [5-8]. Additionally, as a multifunctional natural polyphenolic material, TA has found many uses in food, cosmetic, and pharmaceutical industries [1,9]. Moreover, TA has the ability to (cross)link and sediment many proteins due to its functional groups and the highest molecular weight among all the polyphenols $[10,11]$. Recently, TA has been used in wound dressing applications as a promising biomaterial to prevent infections and promote healing [12,13]. TA molecules capable of effective interactions with other materials by means of hydrogen bonding, ionic bonding, and complex formation as well hydrophobic interactions, and therefore, it has the ability of adhere strongly to various substrates [14,15]. The drug application of TA includes cancer, burns, diarrhea, skin ulcers, and toothaches [16-18]. Due to the versatile bio-beneficial properties of TA, a wide range of different formulations of TA such as bulk hydrogel, microgel/nanogel, film, and fiber forms were prepared and used for different purpose [19-22]. Microgels derived from TA provided many advantages as controllable drug delivery vehicles in pharmaceutical application and as a protection media 
from microbial interactions in food applications [23]. TA microgels were also reported for their capability of selectivity and sensitivity in targeted drug release studied [24,25]. As regulating drug release is important and TA has inherently possessed some medicinal properties and can specifically interact with vast range of molecules and metal ion, the design and utilization of TA microgels as advance, amendable, and long-lasting drug delivery system is reasonable $[26,27]$. Furthermore, to treat a damaged tissue or cells in wound healing applications, TA films were shown successful in aiding to heal the wounds or damaged cells [28]. Additionally, because of the antibacterial properties, TA molecule were incorporated in edible films for food applications as packaging to prevent surface contamination $[29,30]$. Thus, TA molecules in numerous formulations provide many useful products in health, food, and other innovative materials-related applications.

Microgels are a crosslinked network of materials in order of few hundred nm meters to few tens of micrometer [31] and can be commonly prepared in water in an oil reverse micelle system by using different surfactants [32,33]. Surfactant used in preparation of particles requires tedious elimination and cleaning steps and assets an extra coast of the prepared materials that requires a particular attention in commercialization of the products in bulk quantities [34,35]. On the contrary, particles or microgels can also be prepared in surfactant free media rendering practical and viable routes as lesser steps, and chemicals are engaged [36,37]. As microgels are versatile and have a broad range of applications covering food, cosmetic, energy, sensor, and medical fields, a facile and rapid synthesis without using many chemicals makes them more significant in these applications [38-40]. The tunable small sizes and functionality of microgels dignifies the value-added potentials in human-related in vivo applications [41,42].

Here, the preparation of monodisperse poly(tannic acid) $(p(\mathrm{TA}))$ particles for the first time was reported using an oxidizing agent, sodium periodate $\left(\mathrm{NaIO}_{4}\right)$, to render selfcrosslinking of TA molecules in a homogenizer in the surfactant free medium. Hydrolytic degradation of the $p$ (TA) particles prepared by using different amounts of $\mathrm{NaIO}_{4}$ were investigated. To determine the potential blood contacting application of the prepared $p$ (TA) particles, blood compatibility tests by means of hemolysis and blood clotting assays were done. Antioxidant properties of $p$ (TA) particles were investigated by using total phenol content (TPC), ferric reducing antioxidant potential (FRAP), trolox equivalent antioxidant capacity (TEAC), total flavonoid content (TFC), and Fe(II) chelating activity tests. Antibacterial activity of $p(\mathrm{TA})$ particles was also investigated on E. coli as a Gramnegative and $S$. aureus as a Gram-positive bacterium.

\section{Materials and Methods}

\subsection{Materials}

Tannic acid (TA, 99\%, Sigma-Aldrich, St. Louis, MO, USA) as a natural polyphenolic molecule, and sodium periodate $\left(\mathrm{NaIO}_{4}, 99 \%\right.$, Sigma-Aldrich) as oxidizing agents were used as received. Triethylamine (TEA, 99.5\%, Sigma-Aldrich) was used as an accelerator. Cyclohexane (Carlo Erba, Sabadell, Spain, 99\%) was used as the solvent in the particle synthesizing media. Ethanol (Carlo Erba, 99\%), acetone (BRK, technical grade), and DI water $18.2 \mathrm{M} \Omega \mathrm{cm}$ (Millipore-Direct Q UV3) were used for wash solvent of $p(\mathrm{TA})$ particles. Sodium nitrite $\left(\mathrm{NaNO}_{2},>97 \%\right.$ Acros) aluminum chloride $\left(\mathrm{AlCl}_{3}\right.$, Alfa Aesar, Haverhill, MA, USA) was used for TFC test. Iron(II) sulfate heptahydrate $\left(\mathrm{FeSO}_{4} \cdot 7 \mathrm{H}_{2} \mathrm{O}\right.$, Merck, Kenilworth, NJ, USA, 99.5\%), Iron(III) Chloride hexahydrates $\left(\mathrm{FeCl}_{3} \cdot 6 \mathrm{H}_{2} \mathrm{O}, 99 \%\right.$, Acros), and 5,6-Diphenyl-3-(2-pyridyl)-1,2,4-triazine-4,4-disulfonic acid disodium salt hydrate (Alfa Aesar, 99\%) were used for Fe(II) chelating test. Hydrochloric acid ( $\mathrm{HCl}$, SigmaAldrich, $37 \%)$ and sodium acetate anhydrous $\left(\mathrm{CH}_{3} \mathrm{COONa}\right.$, Fisher Scientific, Hampton, $\mathrm{NH}$, USA, 99\%) 2,4,6-tri(2-pyridyl)-s-triazine (Acros, 99\%) were used in Ferric reducing antioxidant power assay (FRAP). Folin Ciocalteu's phenol reagent (Sigma-Aldrich, 99\%) is used for FC Test and potassium persulfate (KPS, 99\%, Sigma-Aldrich, 2,2'-azino-bis(3-ethylbenzothioazoline-6-sulfonic acid) (ABTS, Sigma-Aldrich), ( \pm )-6-hydroxy-2,5,7,8- 
tetramethylchromane-2-carboxylic acid (Trolox, 97\%, Sigma-Aldrich) were used TEAC test. Sodium hydroxide ( $\mathrm{NaOH}$, Merck, $99 \%)$ was used to adjust the $\mathrm{pH}$ of the solutions.

\subsection{Preparation of $p(T A)$ Particles}

The synthesis of TA particles was carried out by dissolving $0.375 \mathrm{~g}$ TA in $1.5 \mathrm{~mL}$ $0.5 \mathrm{M} \mathrm{NaOH}$ solution. Then, this solution was transferred into $50 \mathrm{~mL}$ cyclohexane in $100 \mathrm{~mL}$ flask. Additionally, then, $0.5 \mathrm{~mL}$ aqueous solutions of sodium periodate $\left(\mathrm{NaIO}_{4}\right)$, e.g., 50, 100, and 200 mole\% based on TA amount was added in the solution followed by the addition of $10 \mu \mathrm{L}$ triethylamine (TEA), an accelerator for the reaction by acting as proton acceptor $[43,44]$ and mixed with homogenizer (IKA, T25 digital ULTRA TURRAX) at $5000 \mathrm{rpm}$ at $60^{\circ} \mathrm{C}$ for $45 \mathrm{~min}$. After that, the obtained $p(\mathrm{TA})$ particles were precipitated by using a centrifuge (BECKMAN COULTER, Allegra 64R Centrifuge) at 10,000 rpm for $10 \mathrm{~min}$. Then, $p(\mathrm{TA})$ particles was washed with a DI water:ethanol (1:2.5 by volume ratio) mixture, and just $30 \mathrm{~mL}$ of acetone by centrifugation at 10,000 rpm for $10 \mathrm{~min}$. Finally, the particles were dried by using a heat gun at cold setting, and stored in a closed container for further use.

\subsection{Characterization of $p$ (TA) Particles}

The size and morphology of $p(\mathrm{TA})$ particles were assessed by fields emission scanning electron microscopy (FE-SEM, QUANTA 400F, Fields Emission SEM) images. The $p$ (TA) particles were coated with gold to a few nanometers thickness under vacuum, and then the particles were placed on the top of the $1 \times 1 \mathrm{~cm}$ dimensions of carbon tape and put on an aluminum stub. The images were taken by FE-SEM operating at $20 \mathrm{kV}$ voltage.

Fourier Transform Infrared Spectroscopy (FT-IR spectroscopy, Perkin-Elmer Spectrum 100) was employed to corroborate the functional groups of TA and $p(\mathrm{TA})$ particles via attenuated total reflector (ATR) technique. The observed peaks of the relevant functional groups were assigned in $650-4000 \mathrm{~cm}^{-1}$ spectral ranges.

Thermal degradation profiles of $p(\mathrm{TA})$ particles were evaluated via a thermogravimetric analyzer (TGA, SII TG/DTA 6300) in $35-1000{ }^{\circ} \mathrm{C}$ temperature range with $10^{\circ} \mathrm{C} / \mathrm{min}$ heating rate under the $\mathrm{N}_{2}$ flow rate of $200 \mathrm{~mL} / \mathrm{min}$.

The sizes of the particles were examined by a dynamic light scattering instrument (DLS, Brookhaven Ins. Cor., 90 Plus Particle Size Analyzer). $p$ (TA) particles suspension were prepared using $20 \mathrm{mg}$ particles in $40 \mathrm{~mL}$ of DI water. The DLS measurement were carried out using $35 \mathrm{mV}$ solid state detector using a laser with the wavelength of $659 \mathrm{~nm}$. The same $p(\mathrm{TA})$ particle suspensions were utilized in the determination of the surface charge of the particles by employing zeta potential analyzer (Zeta-Pals, Brookhaven Inst. Corp., Holtsville, NY, USA).

\subsection{Hydrolytic Degradation Studies of $p(T A)$ Particles}

The degradation of $p(\mathrm{TA})$ particles prepared by using different $\mathrm{NaIO}_{4}$ amounts, 50, 100, and $200 \%$ by mole based on TA molecule was studied in water (hydrolytically) in phosphate buffered saline solution (PBS, $\mathrm{pH}$ 7.4). $p$ (TA) particles weighing $30 \mathrm{mg}$ were placed into a dialysis membrane (MW cut off:12000), and this membrane was put in $30 \mathrm{~mL}$ of PBS solution. Afterwards, the degradation of $p(\mathrm{TA})$ hydrolytically was monitored in shaking water bath at $37^{\circ} \mathrm{C}$. The amount of degrading TA molecules resulting from degradation of $p$ (TA) particles were determined by measuring the degradation solution absorbance values at $276 \mathrm{~nm}$ by UV-Visible spectroscopy (UV-Vis Spectroscopy, T80+, PG Ins. Ltd., New Delhi, India). The amounts of degrading TA were calculated from a calibration curve that was previously constructed for TA molecules in PBS. All measurements were executed as triplicates and reported with standard deviations.

\subsection{Blood Compatibility Studies of $p(T A)$ Particles}

Different amounts, 2.5, 5, 10, and $20 \mathrm{mg}$ of $p$ (TA) particles used that were prepared by using $200 \mathrm{~mole} \%$ of $\mathrm{NaIO}_{4}$ in the blood compatibility tests via hemolysis and blood clotting 
assays. The blood compatibility assays were performed in accord with the approved process of the Human Research Ethics Committee of Canakkale Onsekiz Mart University (2011-KAEK-27/2020-E.2000045671). Hemolysis and blood clotting assays were given in detail in the Supplementary Materials.

\subsection{Antioxidant Capabilities of $p(T A)$ Particles}

Determination of antioxidant behaviors of $p(\mathrm{TA})$ particles were done by using five different methods: total phenol content (TPC), ferric reducing antioxidant potential (FRAP) assay, trolox equivalent antioxidant capacity (TEAC), also known as ABTS. ${ }^{+}$scavenging assay, total flavonoid content (TFC), and Fe(II) chelating capability in accord with the literature with some minor modifications [45-47]. The details of these antioxidant assays were given in the Supplementary Materials.

\subsection{Antibacterial Study of $p(T A)$ Particles}

Antibacterial activity of $p$ (TA) particles was examined on E. coli (Gram-, ATCC 8739) and S. aureus (Gram+, ATCC 6538) bacteria employing micro-dilution technique. The bacteria were revived from stock at $-20^{\circ} \mathrm{C}$ and incubated for $24 \mathrm{~h}$ at $35^{\circ} \mathrm{C}$ in oven. Next day, the number of bacteria was adjusted to $1 \times 10^{8}$ McFarland 0.5 standard colony forming unit (CFU) $/ \mathrm{mL}$ and contacted with $p(\mathrm{TA})$ particles. For this purpose, different amounts of particles were weighed as 2.5,5,10, and $20 \mathrm{mg}$ and sterilized under UV light at $420 \mathrm{~nm}$ for $1 \mathrm{~min}$. Then, the sterilized $p$ (TA) particles were suspended in $10 \mathrm{~mL}$ of nutrient broth solution and immediately $100 \mu \mathrm{L}$ from bacteria culture were added in the nutrient broth and vortexed for $1 \mathrm{~min}$ at $300 \mathrm{rpm}$. These particles and bacteria containing nutrient broths were incubated at $35^{\circ} \mathrm{C}$ oven for $18-24 \mathrm{~h}$. Next day, to count the colonies and analyze the inhibition effect of the particles, $100 \mu \mathrm{L}$ of nutrient broth directly and according to necessity dilution of nutrient broth were applied with $0.9 \%$ saline solution were planted on nutrient agar. The nutrient agars were incubated at $35^{\circ} \mathrm{C}$ oven for $24 \mathrm{~h}$ and next day, the colonies of bacteria were counted.

\section{Results and Discussions}

\subsection{Characterization of $p$ (TA) Particles}

As TA is a polyphenol and possesses many hydroxyl groups that makes it easy to react and modify with other molecules. The functionalization of TA is generally carried out by using these abundant numbers of hydroxyl groups to obtain versatile TA derived materials in particularly for food and clinical applications. Therefore, taking the advantage of higher hydroxyl groups, galloyl groups of TA, it can be readily oxidized with a strong oxidant such as $\mathrm{NaIO}_{4}$ and converted to quinone groups using TEA as catalyst [20,48]. Then, with sequential oxidations, decarboxylation, and aldehyde formation, the crosslinking between TA molecules were done via covalent bonds generating $p(\mathrm{TA})$ particles in a surfactant free media by rigorously mixing at $5000 \mathrm{rpm}$ under basic conditions. The schematic representation of $p(\mathrm{TA})$ particles preparation was shown in Figure 1.

(a)

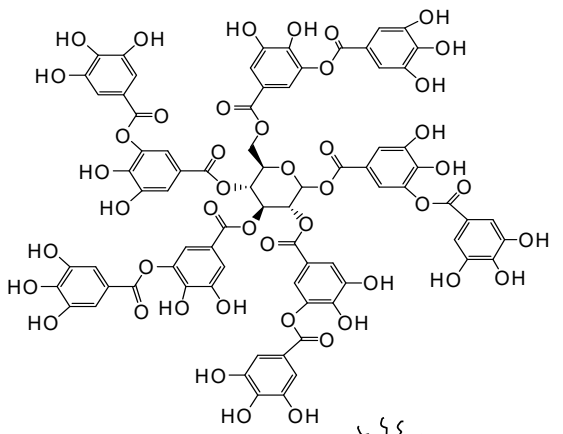

Tannic Acid (TA): (b)

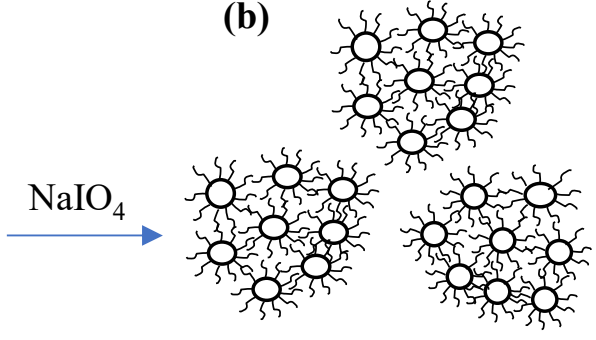

$\mathrm{p}$ (TA) particles

Figure 1. Schematic representation of (a) poly(tannic acid) (b) ( $p(\mathrm{TA}))$ particle preparation. 
The digital camera images of TA molecules and after formation of $p$ (TA) particles in surfactant free media is given in Figure $2 a, b$, respectively. The discernible yellow color change to brown is the clear indication of particle formation. The optical microscope and SEM images, demonstrated in Figure $2 c, d$, respectively, further ascertain the $p$ (TA) particle formation. As can be clearly seen from the SEM images of $p$ (TA) particles (Figure 2d), $p$ (TA) particles are non-spherical (irregular, ellipsoidal). Moreover, additional SEM images were given in Supplementary Figure S1 further corroborates the ellipsoidal shapes of the prepared $p$ (TA) particles. Regardless of the used amounts of oxidizing agents, $\mathrm{NaIO}_{4}$, the obtained particles are almost about the same size with non-spherical shapes (SEM images are not shown).

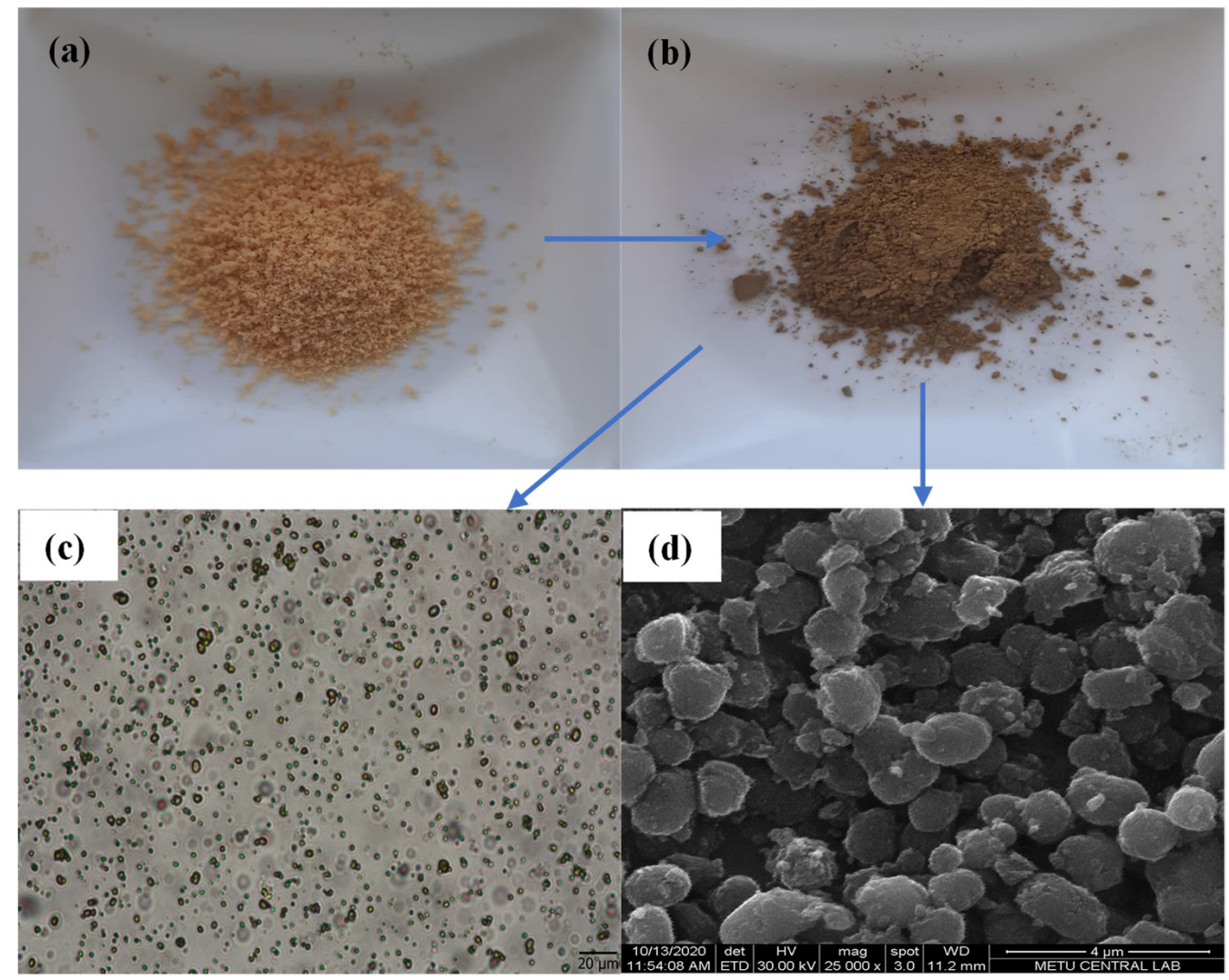

Figure 2. Digital camera image of (a) TA molecule, (b) $p$ (TA) particles, (c) microscope image of $p$ (TA) particles suspended in DI water, and (d) SEM image of $p(\mathrm{TA})$ particles.

In Table 1 , the sizes of $p$ (TA) particles prepared by using 50, 100, and 200 mole $\% \mathrm{NaIO}_{4}$, were measured as $1582 \pm 120,1325 \pm 116$, and $981 \pm 76 \mathrm{~nm}$, respectively. As anticipated, the higher the amounts of oxidizing agent, the smaller the size of $p$ (TA) particles. Although, the preparation of $p$ (TA) without use of any surfactant is simple and easy, the gravimetric yields are low. As shown in Table 1, the yields of 50, 100, and 200\% $\mathrm{NaIO}_{4}$ used $p$ (TA) particles were calculated as $18 \pm 5,20 \pm 6$, and $25 \pm 5 \%$, respectively. Although, the yield is low, the advantages of $p$ (TA) particles synthesis directly with TA molecules via self-crosslinking and without the use of surfactant along with short reaction time, e.g., $45 \mathrm{~min}$ provide great advantages in the biomedical and food applications of the prepared $p$ (TA) particles. As this method is facile, simple, clean (surfactant free), and economically feasible, the prepared $p$ (TA) particles can furnish new avenues in the utilization for the other fields such as sensor, theranostic, and other device applications. 
Table 1. The sizes $(\mathrm{nm}) *$, zeta potential $(\mathrm{mV})$, and gravimetric yields $(\%)$ of $p(\mathrm{TA})$ particles prepared by using different amounts of $\mathrm{NaIO}_{4}$ as mole\% based on TA molecules particles.

\begin{tabular}{cccc}
\hline Particles/NaIO $\mathbf{4} \%$ & Particle Sizes (nm) & Zeta Potential (mV) & Yield (\%) \\
\hline$p(\mathrm{TA}) / 50 \%$ & $1582 \pm 120$ & $-20 \pm 3$ & $18 \pm 5$ \\
$p(\mathrm{TA}) / 100 \%$ & $1325 \pm 116$ & $-24 \pm 2$ & $20 \pm 6$ \\
$p(\mathrm{TA}) / 200 \%$ & $981 \pm 76$ & $-22 \pm 4$ & $25 \pm 5$ \\
\hline
\end{tabular}

${ }^{*}$ Measured by DLS.

The surface charge of the materials, directly related with surface functional groups, is very important in the determination of the application potential of the materials. As the surface characteristic for a given material can significantly affect the physical and chemical properties, hence influencing its utilization in different fields including wastewater treatment or prevention biofilm formation, biomolecule absorption/separation, and release, etc. [49]. As illustrated in Table 1, all the prepared $p(\mathrm{TA})$ particles possess negative surface charges, about $-23 \mathrm{mV}$ that are independent form the used amounts of $\mathrm{NaIO}_{4}$ during synthesis establishing the similar or the same functional groups, e.g., - $\mathrm{OH}$ groups. Therefore, the extent of crosslinking does not affect the surface feature of $p(\mathrm{TA})$ materials.

Thermal stability of $p(\mathrm{TA})$ particles prepared by different crosslinking ratio was investigated and compared with naive TA molecule via TGA in $30-1000{ }^{\circ} \mathrm{C}$ range as shown in Figure 3a. TA molecule was started to degrade at $30{ }^{\circ} \mathrm{C}$ and there was slight degradation until about $240{ }^{\circ} \mathrm{C}$ with $5 \mathrm{wt} \%$ that can be attributed the loss moisture. On the other hand, TA molecule was found to degrade between $240-245^{\circ} \mathrm{C}$ with almost $100 \%$ weight loss as seen in Figure 3a. The thermogram of $p(\mathrm{TA}) / 200 \mathrm{X}$ was revealed 3 degradation steps, the first step is in $395-530{ }^{\circ} \mathrm{C}$ range with the weight loss of $60 \%$, and the second one is in $531-706{ }^{\circ} \mathrm{C}$ with $80 \%$ weight loss, and lastly, in $855-1000{ }^{\circ} \mathrm{C}$ with the final weight loss of about $90 \%$.

The thermal degradation of $p(\mathrm{TA}) / 100 \mathrm{X}$ was also revealed the same number of degradation steps with $p$ (TA) $/ 200 \mathrm{X}$. The first step was completed in $420-540{ }^{\circ} \mathrm{C}$ with a weight loss of $40 \%$. The second degradation was in $541-813^{\circ} \mathrm{C}$ with the weight loss of $60 \%$, and last step was in $814-1000{ }^{\circ} \mathrm{C}$ with the total weight loss was detected as $77 \%$. Thermal degradation of $p(\mathrm{TA}) / 50 \mathrm{X}$ was different as 2 degradation steps were observed. First, between $421-534{ }^{\circ} \mathrm{C}$, the weight loss value of $40 \%$, and the second one in $535-1000{ }^{\circ} \mathrm{C}$ range with a total weight loss value of $74 \%$. According to thermal degradation profiles of the prepared $p$ (TA) particles, the extent of crosslinking is undeniably affecting the particles degradation profiles, and even though $p$ (TA)/200X was prepared by the highest ratio of $\mathrm{NaIO}_{4}$ used, it showed the higher amounts of thermal degradation, $\sim 90 \%$. Therefore, the higher the amount of crosslinker, the higher the amount of total weight loss of the $p(\mathrm{TA})$ particles up to heating $1000^{\circ} \mathrm{C}$. Overall, the TGA results confirms that $p(\mathrm{TA})$ particles can be crosslinked by different extent of crosslinker ratio depending on the used amount of oxidizing agent.

FT-IR analysis is commonly used for the materials to validate the functional groups in their structure. As illustrated in Figure 3b, TA molecules possess the characteristic peaks at $3550-3200 \mathrm{~cm}^{-1}$ as $\mathrm{OH}$ functional group that are present in gallic acid units, and -CHpeaks were seen in 2000-1650 $\mathrm{cm}^{-1}$ stretching frequency range. TA molecule has $\mathrm{C}=\mathrm{O}$ group bending at $1700 \mathrm{~cm}^{-1}$ because of the carboxylic esters from gallic acid units. Upon predominantly intermolecular crosslinking of TA molecules using $\mathrm{NaIO}_{4}$ as oxidizing agent, the $\mathrm{C}=\mathrm{O}$ peaks shifted to lower stretching frequencies as ketone at about $1670 \mathrm{~cm}^{-1}$. Although the mechanism is not fully unveiled, the gallic acids were oxidized with $\mathrm{NaIO}_{4}$ and the quinone groups were generated on TA molecules along with some aldehyde and carboxylic acid groups that can be used in the crosslinking reaction of TA molecules to generate particles $/$ microgels. In $p(\mathrm{TA})$ particles, $\mathrm{C}=\mathrm{C}$ stretching bending at $1560 \mathrm{~cm}^{-1}$ as cyclic alkene, and phenolic -OH bending at $1360 \mathrm{~cm}^{-1}$ was observed at different stretching frequencies than TA molecule. The stretching for $\mathrm{C}-\mathrm{O}$ and $\mathrm{CO}-\mathrm{O}-\mathrm{CO}$ present in $p(\mathrm{TA})$ particles was shifted to higher wavenumbers and the intensities were increased as can be 
seen at 1111 , and $1045 \mathrm{~cm}^{-1}$, respectively, in comparison to TA molecules. For the $p$ (TA) particles prepared by using different mole ratio of oxidizing agent, it is prudent to say that the increased amount of oxidizing agent leads to higher extent of crosslinking resulting increased intensities of the corresponding FT-IR peaks in $p(\mathrm{TA})$ particles.
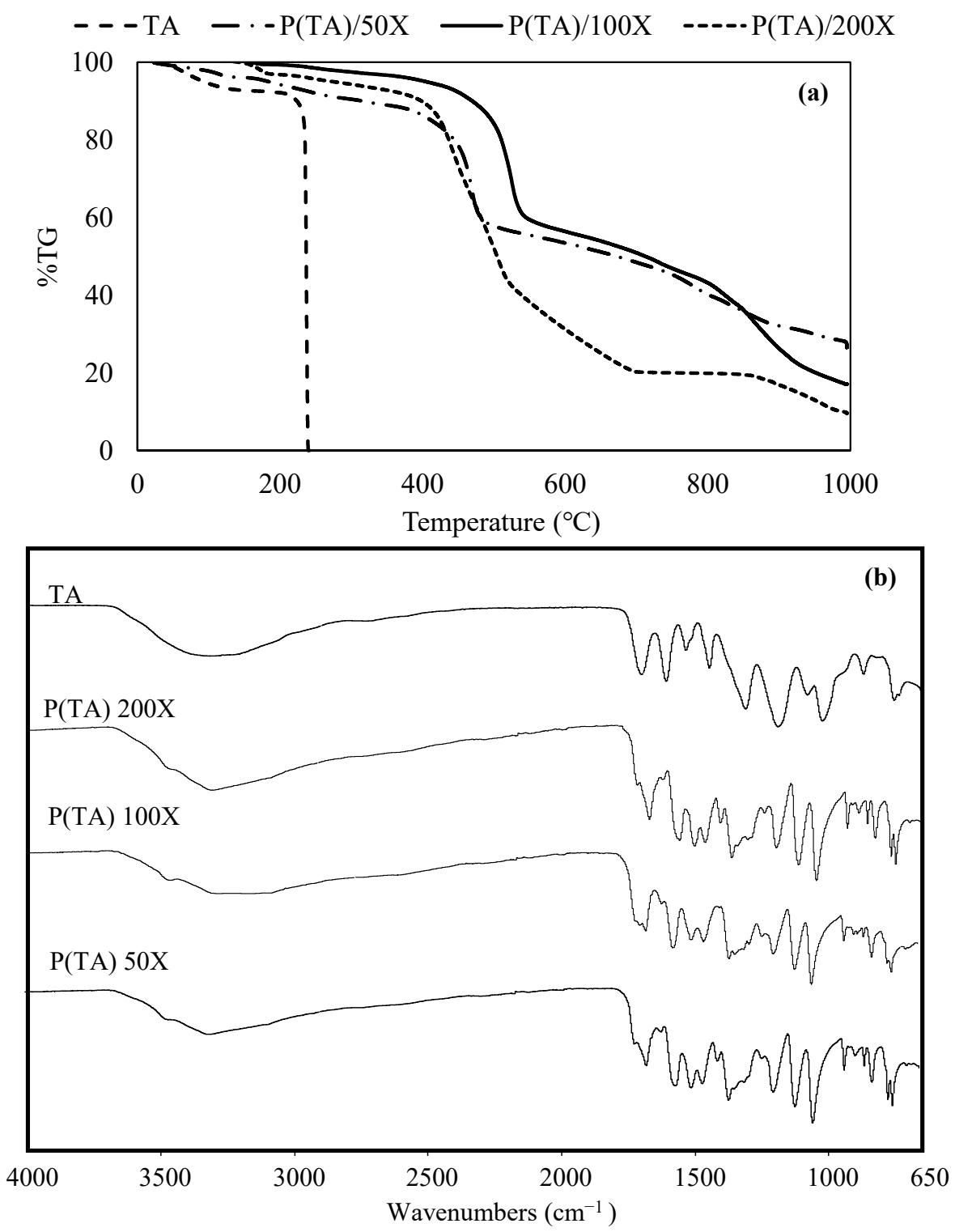

Figure 3. (a) Thermal degradation profiles and (b) FT-IR spectra of TA molecule and $p$ (TA) particles prepared at different crosslinking ratio.

\subsection{Degradation of $p(T A)$ Particles}

The degradation of functional material to manage the release rate and amounts of the active agent is very important in therapeutic utilization of the materials. Depending on the used field, non-degradability, partial degradability, and the controlled degradability allow to regulate discharging of molecules from the carrier for the desired functions and action. Non-degradable or slightly degradable materials can be advantages for long term utilization of the materials provided that they possess innate characteristics such as anticancer, antioxidant, antibacterial, antiallergenic, anti-inflammatory, antistatic, etc. For example, medical textiles or band-aids that contain anti-inflammatory medicine prevent infections in the long-term by covering of open wounds/scars and/or second- and third-degree burns. Therefore, the degradation $p(\mathrm{TA})$ particles prepared with different crosslinking ratios were investigated for 15 days depending at $\mathrm{pH} 7.4$, and the corresponding graph is 
illustrated in Figure 4. It is apparent that the degradation $p(\mathrm{TA})$ particles were increased gradually until the end of one day, regardless of the used amounts of oxidizing agent, and $p(\mathrm{TA}) / 50 \mathrm{X}$ and $p(\mathrm{TA}) / 100 \mathrm{X}$ particles degradation was found relatively slightly more than $p$ (TA)/200X particles.

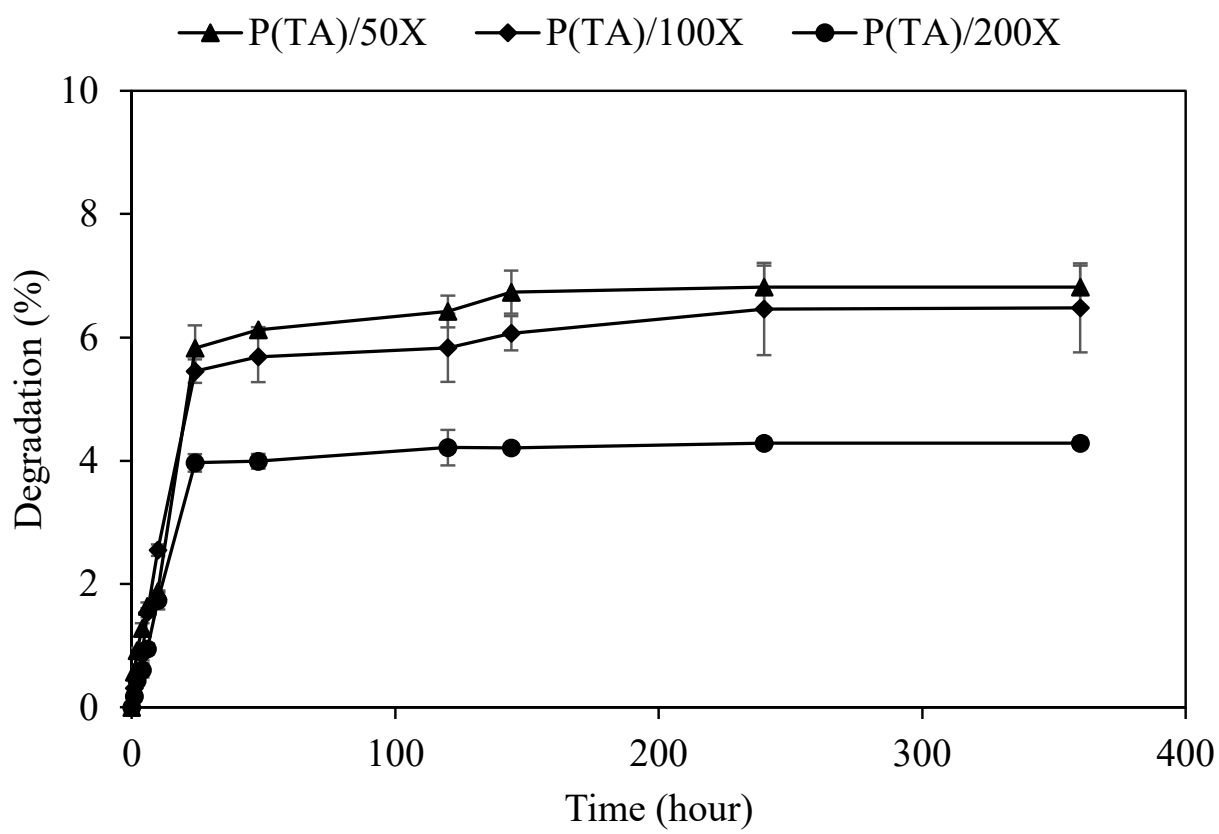

Figure 4. Hydrolytic degradation of $p$ (TA) particles in $\mathrm{pH} 7.4$, PBS solution prepared at different crosslinking ratios.

At the end of $24 \mathrm{~h}$, the degradation of $p(\mathrm{TA})$ particles, crosslinked at 50, 100, and $200 \mathrm{~mole} \%$, was measured as $5.8 \pm 0.4,5.4 \pm 0.2$, and $3.9 \pm 03 \%$, respectively. Subsequently, the degradation of the particles was slightly increased up to $240 \mathrm{~h}$ (10 days), except $p(\mathrm{TA}) / 200 \mathrm{X}$, as the degradation was halted after $24 \mathrm{~h}$. The degradation of $p(\mathrm{TA}) / 50 \mathrm{X}$, $p$ (TA)/100X, and $p$ (TA)/200X particles was completed after $6.8 \pm 0.2,6.5 \pm 0.8$, and $4.3 \pm 0.3 \%$ degradation, respectively, up to $360 \mathrm{~h}$ (15 days). The $p(\mathrm{TA})$ particles can be degraded into fragments of TA derivatives that were intermolecularly self-crosslinked by means of NaIO4 oxidation, and as the calibration curve was prepared using TA molecules at $276 \mathrm{~nm}$ by UV-Visible spectroscopy, only degraded TA molecules can be measured. Therefore, $p$ (TA) particles can be considered as slightly hydrolytically degradable at $\mathrm{pH}$ 7.4 offering great potential for bio-medicinal applications considering TA molecule possesses broad range of biological functions and assets as antibacterial, anti-cancer, and antioxidant, etc.

\subsection{Blood Compatibility Study of $p$ (TA) Particles}

Blood compatibility of a material is essential for bio-medicinal use, especially in blood contacting and/or in vivo applications. Blood compatibility tests of $p(\mathrm{TA}) / 200 \mathrm{X}$ particles were performed employing hemolysis and blood clotting assays, and the corresponding results were graphed as illustrated in Figure 5a,b, respectively. Hemolysis test detects the damaged red blood cells from exposed hemoglobin molecule. As the hemolysis $\%$ is in the $0-5 \%$ range, the material is recognized as non-hemolytic, nonetheless; if the hemolysis $\%$ is found in $5-100 \%$ in range, the material is recognized as hemolytic. As can be clearly seen in Figure $5 \mathrm{a}$, the hemolysis $\%$ of $p(\mathrm{TA}) / 200 \mathrm{X}$ particles were determined as $0.8 \pm 0.1,2.4 \pm 0.3$, $10.8 \pm 1.5$, and $12.2 \pm 1.0 \%$ at $0.25,0.5,1$, and $2 \mathrm{mg} / \mathrm{mL}$ concentrations, respectively. Therefore, $p(\mathrm{TA}) / 200 \mathrm{X}$ can be regarded as non-hemolytic up to $0.5 \mathrm{mg} / \mathrm{mL}$ concentration, and at particle concentration $>0.5 \mathrm{mg} / \mathrm{mL}$, it can induce hemolysis. As a result, in blood 
contacting application of $p$ (TA)/200X, the safely used amount of $p$ (TA)/200X particles should be at $\leq 0.5 \mathrm{mg} / \mathrm{mL}$.
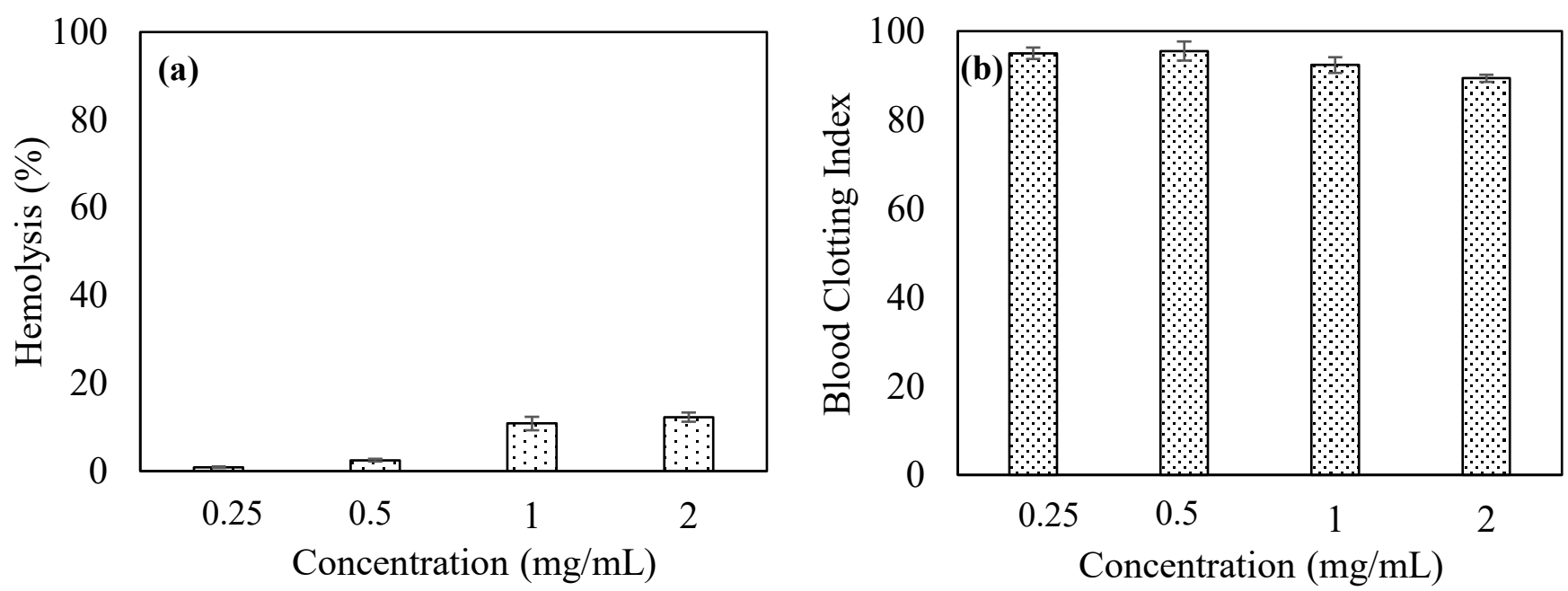

Figure 5. (a) Hemolysis and (b) blood clotting index at various concentration of $p(\mathrm{TA}) / 200 \mathrm{X}$ particles.

Blood clotting assay is another means of testing of the materials to determine the effect of materials on the blood so that the interference on the clotting mechanism can be deciphered. According to the blood clotting index, the field of the material application can be determined, i.e., if a material is planned to be used as a wound dressing material, it will be beneficial to possess a blood clotting effect for the material. If the blood clotting index of a material is $\geq 100$, it effects the blood clotting mechanism positively and if the index is $<100$, that shows the material has a positive effect on blood clotting mechanism. The effect of $p(\mathrm{TA})$ particles on the blood clotting mechanism was determined and shown in Figure 5b. The blood clotting index of $p(\mathrm{TA}) / 200 \mathrm{X}$ particles were found as $95.0 \pm 1.3$, $95.5 \pm 2.1,92.4 \pm 1.7$, and $89.4 \pm 0.7$ at various concentrations, $0.25,0.5,1.0$, and $2.0 \mathrm{mg} / \mathrm{mL}$. Therefore, the blood clotting index results of $p(\mathrm{TA})$ particles revealed that $p(\mathrm{TA})$ particles possessed a slight effect on blood clotting mechanism up to $2.0 \mathrm{mg} / \mathrm{mL}$. Therefore, the usage of $p(\mathrm{TA})$ up to $2.0 \mathrm{mg} / \mathrm{mL}$ particle concentration can be considered safe to use in blood contacting related applications.

\subsection{Antioxidant Capabilities of $p$ (TA) Particles}

The harmful effects of free radicals for human body is very well-known, as they can lead to apoptosis of normal cells, and moreover, they are responsible for many disorders and diseases, including degenerative eye diseases, cancers, diabetes, etc. [50]. TA molecule is well documented for its antioxidant acreage and TA-based materials in many formulations is often used as an antioxidant remedy [51]. The antioxidant capabilities of $p$ (TA)/200X particles were examined by means of total phenol content (TPC), ferric reducing antioxidant potential (FRAP) assays, and trolox equivalent antioxidant capacity (TEAC), also known as $\mathrm{ABTS}^{+}$scavenging radicals, [46,47]. As each assay employs different methods and TA molecule possess versatile functionalities, the utilization of multiple antioxidant tests is justified. Gallic acid and quercetin were used as standard antioxidant materials in TPC, FRAP, and TEAC methods. The antioxidant activity of $p$ (TA)/200X particles were investigated with TPC, FRAP, and TEAC methods, and the corresponding results are summarized in Table 2. As can be seen, these assays resulted in $202.0 \pm 2.0$ and $10.6 \pm 0.6 \mu \mathrm{g} / \mathrm{mL}$ for TPC and FRAP assay, respectively, and $5.8 \pm 0.1 \mathrm{mM}$ Trolox equivalent/g for TEAC. 
Table 2. Total phenol content (TPC, gallic acid equivalent phenol content), ferric reducing antioxidant potential (FRAP), and trolox equivalent antioxidant (TEAC) capacity of $p$ (TA)/200X particles, $0.25 \mathrm{mg} / \mathrm{mL}$.

\begin{tabular}{cccc}
\hline Sample & $\begin{array}{c}\text { Total Phenol Content } \\
(\text { TPC) in Terms of Gallic } \\
\text { Acid Equivalency } \\
(\mu \mathrm{g} / \mathrm{mL})\end{array}$ & $\begin{array}{c}\text { Ferric Reducing } \\
\text { Antioxidant Potential } \\
\text { (FRAP) }(\mu \text { mole Fe(III)) }\end{array}$ & $\begin{array}{c}\text { Trolox Equivalent } \\
\text { Antioxidant (TEAC) } \\
\text { Value (mM Trolox } \\
\text { Equivalent/g) }\end{array}$ \\
\hline GA & 250.0 & $399.9 \pm 35.91$ & $9.1 \pm 0.4$ \\
TA & $168.0 \pm 1.0$ & $22.6 \pm 1.2$ & $5.1 \pm 0.3$ \\
p(TA) & $202.0 \pm 2.0$ & $10.6 \pm 0.6$ & $5.8 \pm 0.1$ \\
\hline
\end{tabular}

On the other hand, the antioxidant activity of TA molecule was calculated as $168.0 \pm 1.0 \mu \mathrm{g} / \mathrm{mL}$ for TPC activity, $22.6 \pm 1.2 \mu \mathrm{g} / \mathrm{mL}$ FRAP assay, and $5.1 \pm 0.3 \mathrm{mM}$ Trolox equivalent/g for TEAC activity. The results evidently revealed that TPC and TEAC activity of TA molecule was lower than $p$ (TA) particles; however, FRAP activity of TA molecule was higher in comparison to $p(\mathrm{TA})$ particles. GA as standard antioxidant molecule at $1 \mathrm{mg} / \mathrm{mL}$ concentration of $25 \mu \mathrm{L}$ possesses $399.9 \pm 35.91 \mu \mathrm{m} \mathrm{Fe}(\mathrm{III})$ reducing capacity for FRAP and was shown as $250 \mu \mathrm{g} / \mathrm{mL}$ and $9.1 \mathrm{mM}$ Trolox equivalent/g for TPC and TEAC activity, respectively. Consequently, $p$ (TA) particles possess significant antioxidant activity in comparison to universal standard material, such as GA.

$\mathrm{Fe}$ (II) chelating activity and total flavonoid content (TFC) activity of TA molecule and $p(\mathrm{TA})$ particles were also done at different concentration range and the results were shown in Figure 6a. Fe(II) chelating activity of TA molecule and $p$ (TA) particles dependent on the used concentration as illustrated in Figure 6a. The cleating capacity of TA molecules was calculated as $21.09 \pm 10.72 \%$ for $0.35 \mathrm{mg} / \mathrm{mL}$ concentration, whereas $p(\mathrm{TA})$ particles were able to chelate $98.41 \pm 0.47 \%$ for the same concentration. As the chelating capacity of $p$ (TA) particles more than TA molecules, and this can be attributed to the three-dimensional existence of TA molecules to form particles making it available TA molecules to complex at every possible angle with $\mathrm{Fe}$ (II) ions. Interestingly, further increase the amount of TA molecules slightly increase the $\mathrm{Fe}(\mathrm{II})$ chelating activity $\%$, and the $p(\mathrm{TA})$ particles on the other hand still has $\geq 95 \% \mathrm{Fe}(\mathrm{II})$ chelating capacity in $0.35-1.5 \mathrm{mg} / \mathrm{mL} p(\mathrm{TA})$ concentration.

TFC test results of TA molecule and $p(\mathrm{TA})$ particles at different concentrations were also presented in Figure $6 \mathrm{~b}$. As can be seen, the TFC value of $p(\mathrm{TA})$ particles was determined as $0.5 \pm 0.1 \mathrm{mg} / \mathrm{mL}$ quercetin (QC) equivalent at $0.5 \mathrm{mg} / \mathrm{mL}$ concentration. The TFC value of TA molecule was determined as $0.2 \pm 0.1 \mathrm{mg} / \mathrm{mL}$ equivalent to $\mathrm{QC}$ at the concentration $(0.5 \mathrm{mg} / \mathrm{mL})$. Additionally, both, TA and $p(\mathrm{TA})$ particles showed a linear increase of QC equivalent with the increase in the concentration as the $p$ (TA) particles possessing more expressed increase. Consequently, the TFC of $p$ (TA) particles in terms of QC equivalent is much more than TA molecules at the same concentration, and it is increased to a higher extent as the concentration is increased.

\subsection{Antibacterial Study of $p(T A)$ Particles}

TA molecule is known for its antibacterial aspect in additional to the other natural biological properties $[29,30,52]$. Therefore, the antibacterial activity of $p(\mathrm{TA})$ particles was assessed on E. coli (Gram) and S. aureus $(\mathrm{Gram}+)$ bacteria. Micro-dilution technique, one of the most valid techniques, was used to investigate the potential antibacterial property of $p(\mathrm{TA}) / 200 \mathrm{X}$ particles and the results were shown in Figure 7 for the various concentration of $p(\mathrm{TA})$ particles. As can be seen, $p(\mathrm{TA})$ particles are not found to be as much as effective against E. coli, a Gram-negative bacterium as on S. aureus, a Gram-positive bacterium. $p$ (TA) particles at $20 \mathrm{mg} / \mathrm{mL}$ concentration showed 8.7-fold increase in bacterial activity in comparing to the control that does not contain any particles. Nevertheless, the antibacterial activity of $p(\mathrm{TA})$ particles on $S$. aureus was found to be higher than E. coli at all the studied concentration. The highest effect of $p$ (TA) particles on S. aureus was observed at $20 \mathrm{mg} / \mathrm{mL}$ concentration resulted in above $50 \%$ bacterial inhibition compared to the control samples. 
Decreasing the concentration of particles was found to induce a decrease in the antibacterial activity. Even $2.5 \mathrm{mg} / \mathrm{mL}$ concentration of $p$ (TA) particles showed the least antibacterial activity, which is 40 -fold decreased in the bacterial colony forming of $S$. aureus bacteria. Hence, $p$ (TA) particles retain some antibacterial activity against the S. aureus. Additionally, this can be attributed to the Gram-positive nature of the bacteria that possesses one layer of cell membrane, whereas Gram negative bacteria possess two layers of cell membrane.
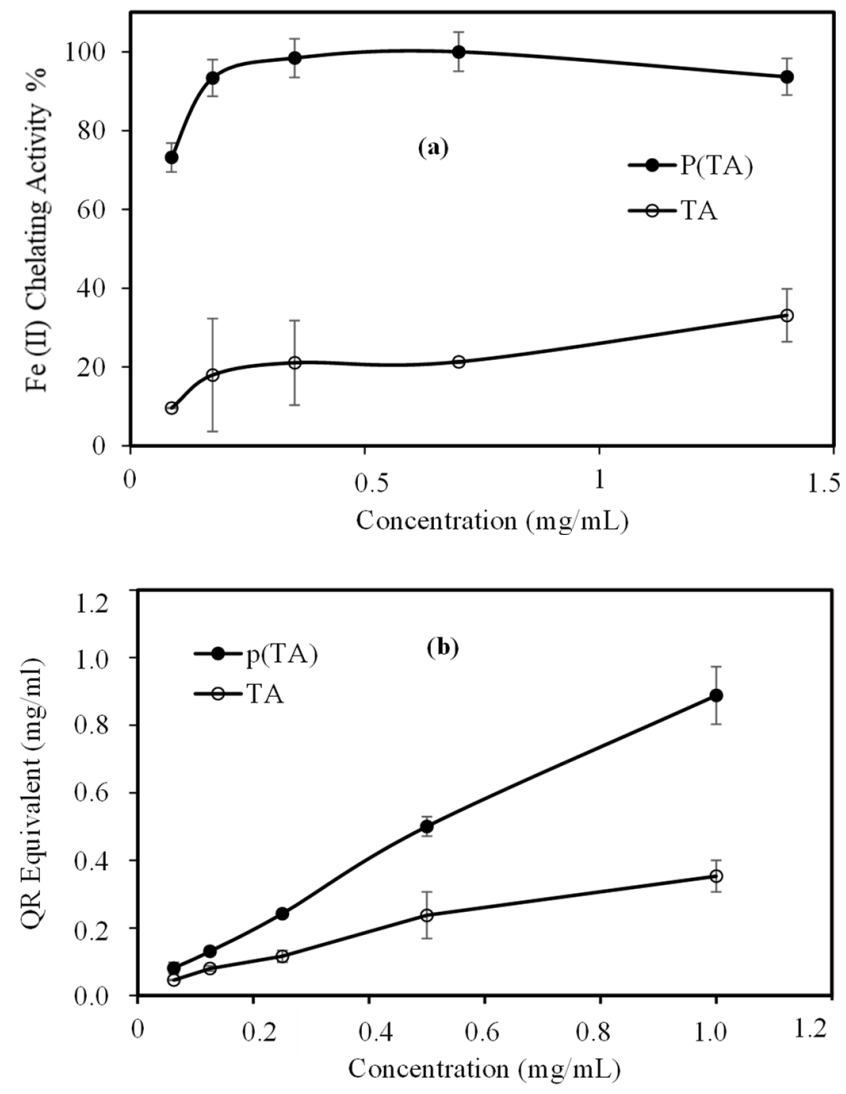

Figure 6. (a) Fe(II) chelating\% of TA and $p$ (TA) particles, and (b) total flavonoid content (TFC) of TA and $p(\mathrm{TA})$ in comparison to quercetin $(\mathrm{QR})$ equivalent.

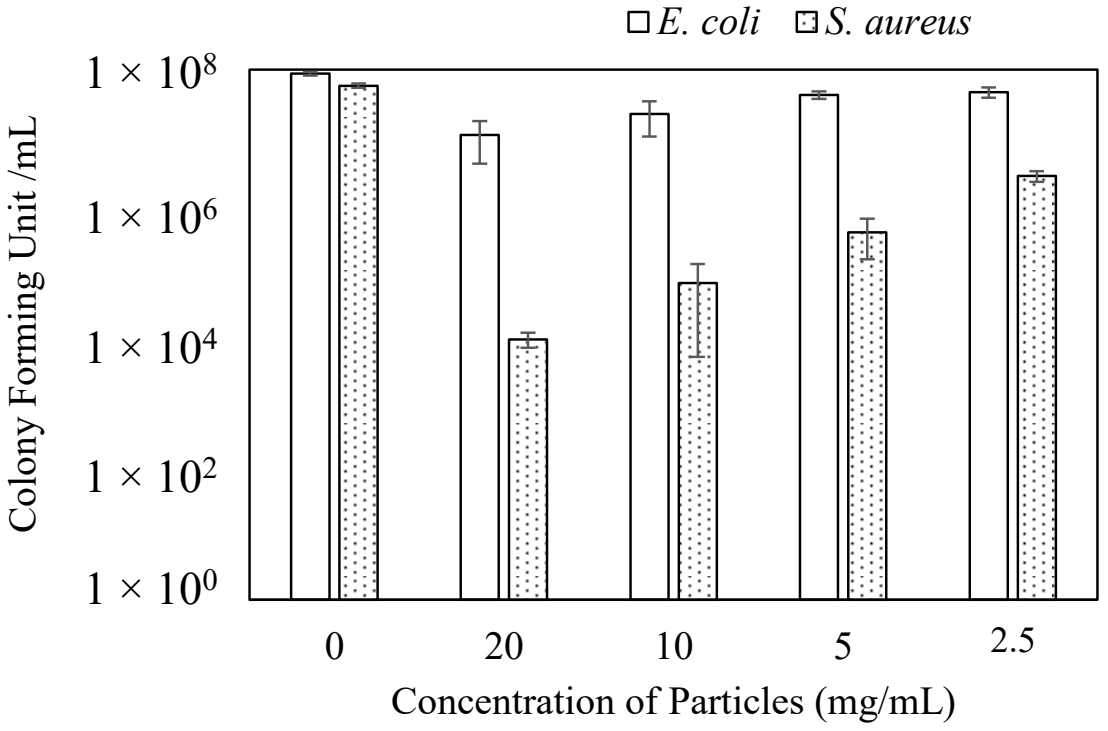

Figure 7. Inhibition of colony forming unit $/ \mathrm{mL}$ depending on concentration $(\mathrm{mg} / \mathrm{mL})$ of $p(\mathrm{TA}) / 200 \mathrm{X}$ particles. 
As a result, $p$ (TA) particles having abundant numbers of hydroxyl groups that can be modifiable provide more potent antibacterial activity in addition to their different antibiotic carrying potential. Thus, $p$ (TA) particles are multifunctional and multipurpose materials and can be used for versatile application.

\section{Conclusions}

Here, a method of self-crosslinking of TA molecule to form $p$ (TA) particles in a surfactant free media is reported for the first time. The method applied for $p$ (TA) particles preparation discloses many advantages as an inexpensive, rapid, facile, and clean method avoiding many tedious and unnecessary uses of extra chemicals such as surfactant, and crosslinkers, chemicals, etc. The use of a simple homogenizer to synthesize almost monodisperse ellipsoidal $p$ (TA) particles in the presence of an oxidant, $\mathrm{NaIO}_{4}$ enabled the oxidation of abundant number of hydroxy groups on the gallic acid groups to quinone bestow self-crosslinking of the TA molecules with each other via covalent bonds. As bonds are irreversibly formed, the highest hydrolytic degradation $\%$ of $p$ (TA) particles prepared by $50 \%$ mole of oxidant $\left(\mathrm{NaIO}_{4}\right)$ were determined about $7 \%$ in 15 days, and lowest degradation was observed as about $4 \%$ for $p$ (TA)/200X. Additionally, $p$ (TA)/200X particles was found as non-hemolytic up to $0.5 \mathrm{mg} / \mathrm{mL}$ and did not interfere with the blood clotting mechanism up to $2 \mathrm{mg} / \mathrm{mL}$ concentration. These self-crosslinked $p$ (TA) particles were shown quite high antioxidant activity that was tested by TPC, FRAP, TEAC, TFC, and Fe(II) chelating ions activity assays compared to TA molecule, except FRAP assay. Furthermore, $p$ (TA) particles were shown to possess better antibacterial activity on Gram positive bacteria than Gram negative bacteria. In conclusion, $p$ (TA) particles retain many biodiverse properties as multifunctional material offering new avenues for diverse bio-medicinal applications.

Supplementary Materials: The following are available online, Self-crosslinked Ellipsoidal Poly(Tannic Acid) Particles for Bio-medical Applications.

Funding: This research received no external funding.

Data Availability Statement: No data is reported.

Acknowledgments: The author is thankful for the assistance from Saliha B. Kurt, Mehtap Sahiner, and Selin S. Suner for their contributions.

Conflicts of Interest: The author declared no conflict of interest.

Sample Availability: Not applicable.

\section{References}

1. Li, R.; Dai, T.; Zhou, W.; Fu, G.; Wan, Y.; McClements, D.J.; Li, J. Impact of pH, ferrous ions, and tannic acid on lipid oxidation in plant-based emulsions containing saponin-coated flaxseed oil droplets. Food Res. Int. 2020, 136, 109618. [CrossRef]

2. Ahmed, G.H.G.; Laíno, R.B.; Calzón, J.A.G.; García, M.E.D. Fluorescent carbon nanodots for sensitive and selective detection of tannic acid in wines. Talanta 2015, 132, 252-257. [CrossRef] [PubMed]

3. Hu, X.; Wang, H.; Lv, X.; Chu, L.; Liu, Z.; Wei, X.; Chen, Q.; Zhu, L.; Cui, W. Cardioprotective Effects of Tannic Acid on Isoproterenol-Induced Myocardial Injury in Rats: Further Insight into 'French Paradox'. Phytother. Res. 2015, 29, 1295-1303. [CrossRef] [PubMed]

4. Zhu, F.; Chu, X.; Wang, H.; Zhang, X.; Zhang, Y.; Liu, Z.; Guo, H.; Liu, H.; Liu, Y.; Chu, L.; et al. New Findings on the Effects of Tannic Acid: Inhibition of L-Type Calcium Channels, Calcium Transient and Contractility in Rat Ventricular Myocytes. Phytother. Res. 2016, 30, 510-516. [CrossRef] [PubMed]

5. Ekambaram, S.P.; Perumal, S.S.; Balakrishnan, A. Scope of Hydrolysable Tannins as Possible Antimicrobial Agent. Phytother. Res. 2016, 30, 1035-1045. [CrossRef] [PubMed]

6. Hazer, B.; Ashby, R.D. Synthesis of a novel tannic acid-functionalized polypropylene as antioxidant active-packaging materials. Food Chem. 2021, 344, 128644. [CrossRef] [PubMed]

7. Chowdhury, P.; Nagesh, P.K.; Hatami, E.; Wagh, S.; Dan, N.; Tripathi, M.K.; Khan, S.; Hafeez, B.B.; Meibohm, B.; Chauhan, S.C.; et al. Tannic acid-inspired paclitaxel nanoparticles for enhanced anticancer effects in breast cancer cells. J. Colloid Interface Sci. 2019, 535, 133-148. [CrossRef]

8. Rahimi, J.; Bahrami, N.; Niksefat, M.; Kamalzare, M.; Maleki, A. A novel biodegradable magnetic bionanocomposite based on tannic acid as a biological molecule for selective oxidation of alcohols. Solid State Sci. 2020, 105, 106284. [CrossRef] 
9. Serrano, J.; Puupponen-Pimiä, R.; Dauer, A.; Aura, A.-M.; Calixto, F.D.S. Tannins: Current knowledge of food sources, intake, bioavailability and biological effects. Mol. Nutr. Food Res. 2009, 53 (Suppl. 2), S310-S329. [CrossRef] [PubMed]

10. Pinto, A.F.; Nascimento, J.M.D.; Sobral, R.V.D.S.; De Amorim, E.L.C.; Silva, R.O.; Leite, A.C.L. Tannic acid as a precipitating agent of human plasma proteins. Eur. J. Pharm. Sci. 2019, 138, 105018. [CrossRef]

11. Adamczyk, B.; Simon, J.; Kitunen, V.; Adamczyk, S.; Smolander, A. Tannins and Their Complex Interaction with Different Organic Nitrogen Compounds and Enzymes: Old Paradigms versus Recent Advances. ChemistryOpen 2017, 6, 610-614. [CrossRef]

12. Xu, F.; Weng, B.; Gilkerson, R.; Materon, L.A.; Lozano, K. Development of tannic acid/chitosan/pullulan composite nanofibers from aqueous solution for potential applications as wound dressing. Carbohydr. Polym. 2015, 115, 16-24. [CrossRef] [PubMed]

13. Taheri, P.; Jahanmardi, R.; Koosha, M.; Abdi, S. Physical, mechanical and wound healing properties of chitosan/gelatin blend films containing tannic acid and/or bacterial nanocellulose. Int. J. Biol. Macromol. 2020, 154, 421-432. [CrossRef] [PubMed]

14. Fan, H.; Wang, J.; Zhang, Q.; Jin, Z. Tannic Acid-Based Multifunctional Hydrogels with Facile Adjustable Adhesion and Cohesion Contributed by Polyphenol Supramolecular Chemistry. ACS Omega 2017, 2, 6668-6676. [CrossRef] [PubMed]

15. Fan, H.; Wang, L.; Feng, X.; Bu, Y.; Wu, D.; Jin, Z. Supramolecular Hydrogel Formation Based on Tannic Acid. Macromolecules 2017, 50, 666-676. [CrossRef]

16. Farha, A.K.; Yang, Q.-Q.; Kim, G.; Li, H.-B.; Zhu, F.; Liu, H.-Y.; Gan, R.-Y.; Corke, H. Tannins as an alternative to antibiotics. Food Biosci. 2020, 38, 100751. [CrossRef]

17. Antonia, D.S.L.; Laynne, H.D.C.L.; Davi, D.S.; Livio, C.C.N.; Jose, A.D.L. Incorporation of tannic acid in formulations for topical use in wound healing: A technological prospecting. Afr. J. Pharm. Pharmacol. 2015, 9, 662-674. [CrossRef]

18. Baer-Dubowska, W.; Szaefer, H.; Majchrzak-Celińska, A.; Krajka-Kuźniak, V. Tannic Acid: Specific Form of Tannins in Cancer Chemoprevention and Therapy-Old and New Applications. Curr. Pharmacol. Rep. 2020, 6, 28-37. [CrossRef]

19. Sahiner, N.; Sagbas, S.; Sahiner, M.; Demirci, S. Degradable tannic acid/polyethyleneimine polyplex particles with highly antioxidant and antimicrobial effects. Polym. Degrad. Stab. 2016, 133, 152-161. [CrossRef]

20. Allais, M.; Mailley, D.; Hébraud, P.; Ihiawakrim, D.; Ball, V.; Meyer, F.; Hébraud, A.; Schlatter, G. Polymer-free electrospinning of tannic acid and cross-linking in water for hybrid supramolecular nanofibres. Nanoscale 2018, 10, 9164-9173. [CrossRef] [PubMed]

21. Li, T.; Xiao, Y.; Guo, D.; Shen, L.; Li, R.; Jiao, Y.; Xu, Y.; Lin, H. In-situ coating $\mathrm{TiO}_{2}$ surface by plant-inspired tannic acid for fabrication of thin film nanocomposite nanofiltration membranes toward enhanced separation and antibacterial performance. $J$. Colloid Interface Sci. 2020, 572, 114-121. [CrossRef] [PubMed]

22. Tang, C.-Y.; Yu, P.; Tang, L.-S.; Wang, Q.-Y.; Bao, R.-Y.; Liu, Z.-Y.; Yang, M.-B.; Yang, W. Tannic acid functionalized graphene hydrogel for organic dye adsorption. Ecotoxicol. Environ. Saf. 2018, 165, 299-306. [CrossRef] [PubMed]

23. Koopmann, A.-K.; Schuster, C.; Torres-Rodríguez, J.; Kain, S.; Pertl-Obermeyer, H.; Petutschnigg, A.; Hüsing, N. Tannin-Based Hybrid Materials and Their Applications: A Review. Molecules 2020, 25, 4910. [CrossRef] [PubMed]

24. Wang, Y.; Guo, L.; Dong, S.; Cui, J.; Hao, J. Microgels in biomaterials and nanomedicines. Adv. Colloid Interface Sci. 2019, 266, 1-20. [CrossRef]

25. Agili, F.A.; Aly, S.F. Physicochemical characterization and release properties of oral drug delivery: A pH-sensitive nanocomposite based on sodium alginate-pectin-tannic acid-silver. Polym. Polym. Compos. 2020, 28, 598-608. [CrossRef]

26. Abouelmagd, S.A.; Ellah, N.H.A.; Amen, O.; Abdelmoez, A.; Mohamed, N.G. Self-assembled tannic acid complexes for pHresponsive delivery of antibiotics: Role of drug-carrier interactions. Int. J. Pharm. 2019, 562, 76-85. [CrossRef] [PubMed]

27. Javanbakht, S.; Shadi, M.; Mohammadian, R.; Shaabani, A.; Ghorbani, M.; Rabiee, G.; Amini, M.M. Preparation of $\mathrm{Fe}_{3} \mathrm{O}_{4} @ \mathrm{SiO}_{2} @$ Tannic acid double core-shell magnetic nanoparticles via the Ugi multicomponent reaction strategy as a pH-responsive co-delivery of doxorubicin and methotrexate. Mater. Chem. Phys. 2020, 247, 122857. [CrossRef]

28. Kaczmarek, B.; Wekwejt, M.; Nadolna, K.; Owczarek, A.; Mazur, O.; Pałubicka, A. The mechanical properties and bactericidal degradation effectiveness of tannic acid-based thin films for wound care. J. Mech. Behav. Biomed. Mater. 2020, 110, 103916. [CrossRef] [PubMed]

29. Picchio, M.L.; Linck, Y.G.; Monti, G.A.; Gugliotta, L.M.; Minari, R.J.; Igarzabal, C.I.A. Casein films crosslinked by tannic acid for food packaging applications. Food Hydrocoll. 2018, 84, 424-434. [CrossRef]

30. Halim, A.L.A.; Kamari, A.; Phillip, E. Chitosan, gelatin and methylcellulose films incorporated with tannic acid for food packaging. Int. J. Biol. Macromol. 2018, 120, 1119-1126. [CrossRef]

31. Dai, Z.; Ngai, T. Microgel particles: The structure-property relationships and their biomedical applications. J. Polym. Sci. Part A Polym. Chem. 2013, 51, 2995-3003. [CrossRef]

32. Fernandez-Rodriguez, M.A.; Martín-Molina, A.; Maldonado-Valderrama, J. Microgels at interfaces, from mickering emulsions to flat interfaces and back. Adv. Colloid Interface Sci. 2021, 288, 102350. [CrossRef]

33. Taokaew, S.; Ofuchi, M.; Kobayashi, T. Size Distribution and Characteristics of Chitin Microgels Prepared via Emulsified Reverse-Micelles. Materials 2019, 12, 1160. [CrossRef]

34. Bonham, J.A.; Faers, M.A.; Van Duijneveldt, J.S. Non-aqueous microgel particles: Synthesis, properties and applications. Soft Matter 2014, 10, 9384-9398. [CrossRef]

35. Bin Hamzah, Y.; Hashim, S.; Rahman, W.A.W.A. Synthesis of polymeric nano/microgels: A review. J. Polym. Res. 2017, 24, 134. [CrossRef]

36. Thorne, J.B.; Vine, G.J.; Snowden, M.J. Microgel applications and commercial considerations. Colloid Polym. Sci. 2011, 289, 625-646. [CrossRef] 
37. Hua, M.; Du, Y.; Song, J.; Sun, M.; He, X. Surfactant-free fabrication of pNIPAAm microgels in microfluidic devices. J. Mater. Res. 2019, 34, 206-213. [CrossRef]

38. Anakhov, M.V.; Gumerov, R.A.; Potemkin, I.I. Stimuli-responsive aqueous microgels: Properties and applications. Mendeleev Commun. 2020, 30, 555-562. [CrossRef]

39. Kozhunova, E.Y.; Gvozdik, N.A.; Motyakin, M.V.; Vyshivannaya, O.V.; Stevenson, K.J.; Itkis, D.M.; Chertovich, A.V. Redox-Active Aqueous Microgels for Energy Storage Applications. J. Phys. Chem. Lett. 2020, 11, 10561-10565. [CrossRef]

40. Shewan, H.M.; Stokes, J.R. Review of techniques to manufacture micro-hydrogel particles for the food industry and their applications. J. Food Eng. 2013, 119, 781-792. [CrossRef]

41. De Lima, C.S.A.; Balogh, T.S.; Varca, J.P.R.O.; Varca, G.H.C.; Lugão, A.B.; Camacho-Cruz, L.A.; Bucio, E.; Kadlubowski, S.S. An Updated Review of Macro, Micro, and Nanostructured Hydrogels for Biomedical and Pharmaceutical Applications. Pharmaceutics 2020, 12, 970. [CrossRef]

42. Alzanbaki, H.; Moretti, M.; Hauser, C.A.E. Engineered Microgels-Their Manufacturing and Biomedical Applications. Micromachines 2021, 12, 45. [CrossRef] [PubMed]

43. Nalawade, P.; Mukherjee, P.; Kapoor, S. Triethylamine induced synthesis of silver and bimetallic (Ag/Au) nanoparticles in glycerol and their antibacterial study. J. Nanostruct. Chem. 2014, 4, 113. [CrossRef]

44. Gui, Y.; Tian, K.; Liu, J.; Yang, L.; Zhang, H.; Wang, Y. Superior triethylamine detection at room temperature by $\{-112\}$ faceted $\mathrm{WO}_{3}$ gas sensor. J. Hazard. Mater. 2019, 380, 120876. [CrossRef] [PubMed]

45. Fiol, M.; Weckmüller, A.; Neugart, S.; Schreiner, M.; Rohn, S.; Krumbein, A.; Kroh, L.W. Thermal-induced changes of kale's antioxidant activity analyzed by HPLC-UV/Vis-online-TEAC detection. Food Chem. 2013, 138, 857-865. [CrossRef] [PubMed]

46. Li, Y.; Ma, D.; Sun, D.; Wang, C.; Zhang, J.; Xie, Y.; Guo, T. Total phenolic, flavonoid content, and antioxidant activity of flour, noodles, and steamed bread made from different colored wheat grains by three milling methods. Crop J. 2015, 3, 328-334. [CrossRef]

47. Sudan, R.; Bhagat, M.; Gupta, S.; Singh, J.; Koul, A. Iron (FeII) Chelation, Ferric Reducing Antioxidant Power, and Immune Modulating Potential of Arisaema jacquemontii (Himalayan Cobra Lily). BioMed Res. Int. 2014, 2014, 1-7. [CrossRef]

48. Lee, B.P.; Dalsin, J.L.; Messersmith, P.B. Synthesis and Gelation of DOPA-Modified Poly(ethylene glycol) Hydrogels. Biomacromolecules 2002, 3, 1038-1047. [CrossRef] [PubMed]

49. Phillips, I.R.; Sheehan, K.J. Importance of surface charge characteristics when selecting soils for wastewater re-use. Aust. J. Soil Res. 2005, 43, 915-927. [CrossRef]

50. Florence, T.M. The role of free radicals in disease. Aust. N. Z. J. Ophthalmol. 1995, 23, 3-7. [CrossRef]

51. Lou, W.; Chen, Y.; Ma, H.; Liang, G.; Liu, B. Antioxidant and $\alpha$-amylase inhibitory activities of tannic acid. J. Food Sci. Technol. 2018, 55, 3640-3646. [CrossRef] [PubMed]

52. Sahiner, N.; Sagbas, S.; Aktas, N. Preparation of macro-, micro-, and nano-sized poly(Tannic acid) particles with controllable degradability and multiple biomedical uses. Polym. Degrad. Stab. 2016, 129, 96-105. [CrossRef] 